\title{
The interaction of the main actuators of hydraulic excavators
}

\author{
Rustem Nabiullin, Irina Teliman, and Sergey Khoroshavin \\ Ural State Mining University, 620144 Ekaterinburg, Russia
}

\begin{abstract}
The operation modes of the main actuators of hydraulic excavators during their joint operation in the process of rock excavation are considered. It is shown that the main mechanisms for turning the boom of the handle and the bucket are part of hydromechanical units consisting of an engine (hydraulic cylinder) and a main mechanism in which the engine (the cylinder and the rod itself) and elements of the working equipment (boom, handle or bucket) are the links of the mechanism.

It has been established that the relationship between the parameters of the mechanical energy of the engines and the power parameters implemented on the driven (output) links of the mechanisms depend on the magnitude of the extension of the hydraulic cylinder rod. Mathematical models of the main mechanisms are developed. A computational experiment was carried out to determine the actual values of energy-power parameters implemented on the cutting edge of the bucket (teeth) during excavation of rocks at characteristic points of the excavator's working area, as well as reactive loads in the rota-tion mechanisms of the boom and stick.

The proposed methodology for determining the operational parameters of the main mechanisms will allow us to estimate the range of changes in the power parameters implemented on the cutting edge of the bucket in the working area and to identify the relationship between active and reactive loads in the mechanisms due to the serial connection of hydromechanical units.
\end{abstract}

\section{Introduction}

The widespread use of hydraulic mining excavators is due to a number of technical and technological advantages of these machines compared to electromechanical mining excavators, the main of which are:

- the ability to implement all the installed drive power in each actuator;

- increased kinematic mobility of the working body (bucket).

However, in practice, the implementation of these advantages is associated with certain technical difficulties associated with the structural features of the working equipment.

A review of the studies performed [1-9] shows that the substantiation and choice of parameters of the main actuators are not fully considered.

The determination of the operational parameters of the main mechanisms taking into account their kinematic properties and the assessment of the degree of interaction of the mechanisms will reveal the reserves for increasing the efficiency of the operation of hydraulic excavators. 


\section{The purpose and objectives of the study}

The purpose of the study is to increase the efficiency of the hydraulic excavator.

Tasks of work:

- identification of the interdependence between the parameters of the mechanical energy of the engines (hydraulic cylinders) and the power parameters implemented on the driven links of the mechanisms (the boom of the handle and the bucket);

- determination of the relationship between the operational parameters of the rotation mechanism of the bucket functioning in the "active" mode, and reactive loads in the rotation mechanisms of the boom and stick.

\section{Research method}

The object of research is the main mechanisms of a hydraulic excavator, which are a new kind of mechanisms - lever-hydraulic.

The subject of the study is the assessment of the degree of interaction of the main mecha-nisms of hydraulic excavators in the process of rock excavation.

Research methods - methods of the theory of machines and mechanisms, mathematical and simulation modeling, computational experiment.

The main mechanisms as lever-hydraulic mechanisms are distinguished by the fact that they have "individual" kinematic properties, depending on the structural scheme of the mechanism, the type of kinematic connections between the links and the geometric parameters (lengths) of the links.

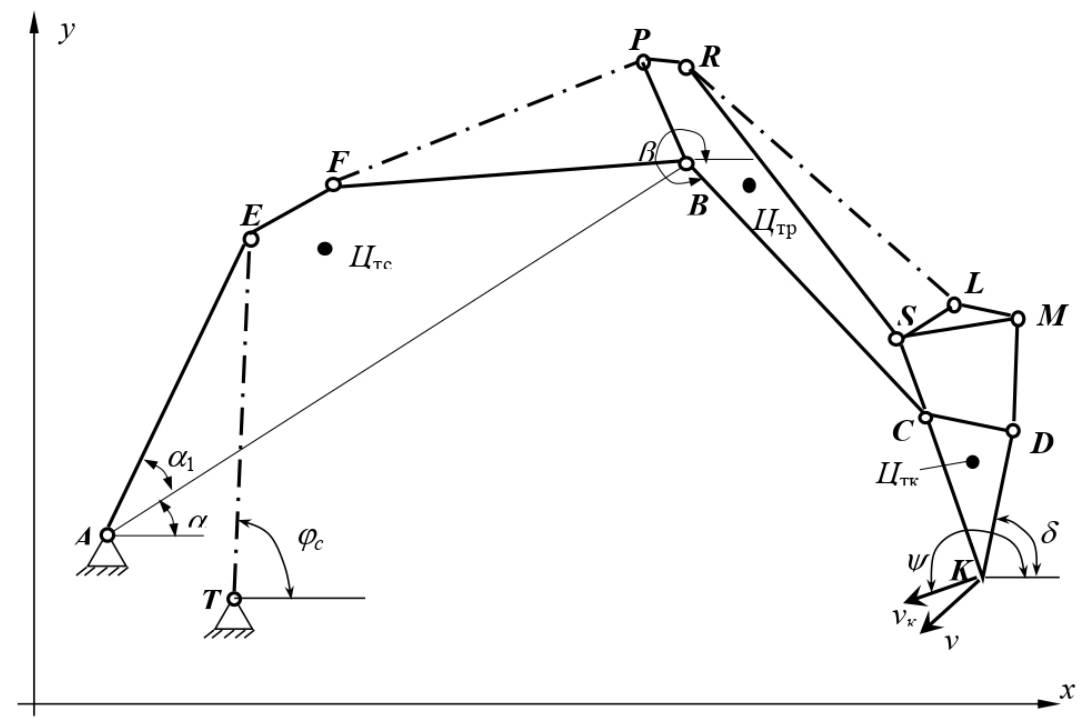

Fig. 1. The scheme for determining the parameters of the working area and the provisions of the elements of the working equipment: $\alpha, \alpha 1, \varphi c, \beta, \psi-$ angles that determine the position of the links of the mechanisms;

The main characteristics of any linkage mechanism are kinematic and dynamic trans-fer functions (such as gear ratios) that determine the correspondence between the engine operating parameters (rod extension speed and the force exerted on the rod) and operating parameters implemented on the driven link, depending on the rod extension value. 
In Fig. 1 shows a diagram of the working equipment of a backhoe of a hydraulic excavator.

The initial data for the construction of the working area are the dimensions of the working equipment, and for the calculation, the distances between the axes of the elements are used. In the table. 1 shows the designations of the elements used to compile the expression for calculating the parameters of the working area.

Table 1. Designation of the source data for calculating the working area.

\begin{tabular}{|l|l|}
\hline Parameter Name & Designation on the scheme \\
\hline Designation on the scheme & $\mathrm{X}_{\mathrm{A}}$ \\
\hline $\begin{array}{c}\text { The coordinates of the axis of the } \\
\text { hinge "heel of the boom-platform", } m\end{array}$ & $\mathrm{Y}_{\mathrm{A}}$ \\
\cline { 2 - 2 } &
\end{tabular}

At the initial stage, a kinematic and power analysis of the main mechanisms was performed.

The kinematic and dynamic transfer functions of the mechanisms are determined.

The transfer functions of the mechanisms in general will be:

Kinematic

to turn the bucket:

$$
K \Pi \Phi_{K}=V_{K} / V_{Г Ц}=f_{1}\left(l_{i}, \varphi_{i}\right)
$$

for boom and stick rotation mechanisms:

Dynamic

$$
K \Pi \Phi_{C(P)}=W_{\text {вед.зв }} / V_{Г Ц}=f_{1}\left(l_{i}, \varphi_{i}\right)
$$

for bucket rotation mechanism:

$$
\text { ДПФ } \Phi_{K}=F_{K} / F_{Г Ц}=f_{2}\left(l_{i}, \varphi_{i}, G_{i}\right) ;
$$

for the mechanism of rotation of the boom and handle:

$$
\text { ДП } \Phi_{C(P)}=M_{\text {вед.3в }} / F_{\text {ГЦ }}=f_{2}\left(l_{i}, \varphi_{i}, G_{i}\right) ;
$$

where is $V_{K}$ - the digging speed (the speed of the tip of the cutting edge of the bucket);

$V_{Г Ц}$ - the speed of the extension of the hydraulic cylinder rod;

$\omega_{\text {вед.зв }}$ - the angular velocity of the driven link;

$F_{K}$-the force acting on the cutting edge of the bucket;

$F_{\Gamma Ц}$-the force acting on the rod of the hydraulic cylinder;

$M_{в е д .36}$ - torque realized on the driven link;

$l_{i}$ - the length of the links;

$\varphi_{i}$ - angles that determine the position of the links;

$G_{i}$ - the forces of gravity of the links.

Mathematical models of the main actuators are developed.

As a research method, a computational experiment is adopted, performed on the basis of mathematical models of the main mechanisms. For algorithmic models, experimenting with the model is identical to finding the values of the output characteristics for given values of the input variables and constant arguments, i.e. substitution of specific numbers into the algorithm and calculation by formulas. Enumeration of solutions is made with a given step 
of variation. During the miscalculation and calibration of the mathematical model, information is accumulated on the functional capabilities of various structural schemes of working equipment. Thus, a computational experiment consists in repeatedly reproducing the functioning (behavior) of the system under study based on a mathematical model.

A computational experiment was performed to calculate the operational parameters of the main mechanisms of the EGO-150 hydraulic excavator manufactured by PJC «Uralmashzavod».

The table shows the values of the kinematic and dynamic transfer functions of the rotation mechanisms of the boom, arm and bucket of the EGO-150 excavator, depending on the magnitude of the relative displacement of the hydraulic cylinder rod.

\section{Results}

From the above data it follows that the form of the dynamic transfer functions and, accordingly, the nature of the change in the forces and torques realized on the driven links of the mechanisms practically coincide for all mechanisms, namely, the values of the power parameters increase as the stem extends, and by the end of the stroke they decrease.

Transfer functions of the main mechanisms

\begin{tabular}{|l|l|l|l|l|l|}
\hline$\Delta \mathrm{L} / \mathrm{L}$ & 0 & 0,25 & 0,5 & 0,75 & 1 \\
\hline \multicolumn{6}{|c|}{ Kinematic functions } \\
\hline ЦС & 6,7 & 5,2 & 5,2 & 6,1 & 9,8 \\
\hline ЦР & 4,3 & 3,0 & 2,9 & 3,3 & 4,7 \\
\hline \multicolumn{6}{|l|}{ Dynamic functions } \\
\hline ЦС & 4,8 & 2,6 & 0,19 & 0,16 & 0,10 \\
\hline ЦР & 0,15 & 0,19 & 0,34 & 0,3 & 0,21 \\
\hline ЦК & 0,23 & 0,33 & 0,40 & 0,36 & 0,27 \\
\hline
\end{tabular}

However, the patterns of changes in external loads acting in the process of functioning of the mechanism are determined by the functional purpose and mode of operation of the mechanism.

So, in the process of excavation of rocks, external loads (the resistance force of the rock to digging and the gravity of the rock supplied to the bucket) are continuously increasing and reach the maximum value by the end of digging.

Therefore, the dynamic transfer function of the mechanism of rotation of the bucket does not provide effective management of the excavation process.

For mechanisms performing transport operations, the level of loading is determined by the value of the "load" moment, i.e. Depends on the departure of the bucket and other elements of the working equipment.

In the mechanisms of rotation of the boom and rotation of the handle at the beginning of the stroke of the rod, the arrow and handle take almost horizontal positions and, accordingly, the level of loading of the mechanisms increases.

The dynamic transfer functions of the rotation mechanisms as the boom extends and the handle rotates also does not correspond to the nature of the change in the appearance of the mechanism.

\section{Findings}

A simulation model of the functioning of the working mechanisms of a mining excavator allows you to establish the ratio of active and reactive loads in the mechanisms of rotation 
of the boom and stick, taking into account the geometric parameters of the working equipment, the type of trajectory of the top of the cutting edge of the bucket and other factors.

Using the proposed model will allow us to evaluate the performance of the excavator at the design stage.

\section{References}

1. P.A. Pobegailo, Powerful single-bucket hydraulic excavators Selecting the basic geometric parameters of the working equipment in the early stages of design, 296 (2014)

2. P. Bules, Mining Journal, 96 (118), 36 (2014)

3. S. Frimpong, Y. Hu, Z. Chung, In Summer in computer simulation conference, 133 (2003)

4. F. Geu Flores, A. Kecskemothy, A. Pottker, 12th IFToMM I World Congress, 6 (2007)

5. A.P. Komissarov, V.S. Shestakov, A simulation model of the functioning of the working equipment of a hydraulic excavator $\mathrm{P}$ Mining equipment and electromechanics, 98, 20 (2013)

6. V.S. Shestakov, S.A. Khoroshavnn, Mining equipment and electromechanics, 8, 14 (2013)

7. A.P. Komissarov, Yu.A. Lagunopa, V.S. Shestakov, Mining Equipment and Electromechanics, 2, 9 (2014)

8. A.P. Komissaryuv, Yu.A. Lagunova, O.A. Lukashuk, I.V. Teliman, Mining Equipment and Electromechanics, 2, 7 (2017)

9. A.P. Komissarjuv, Yu.A. Lagunova, V.S. Shestakov, I.V. Teliman, Scientificanalytical and production journal "Mining Equipment and Electromechanics", 1 (135), 7 (2018) 